\title{
Editorial: Abiotic Stresses in Agroecology: A Challenge for Whole Plant Physiology
}

\author{
Urs Feller $^{1 *}$, Alison H. Kingston-Smith ${ }^{2}$ and Mauro Centritto ${ }^{3}$ \\ ${ }^{1}$ Institute of Plant Sciences and Oeschger Centre for Climate Change Research, University of Bern, Bern, Switzerland, \\ ${ }^{2}$ Institute of Biological, Environmental and Rural Sciences, Aberystwyth University, Aberystwyth, UK, ${ }^{3}$ Tree and Timber \\ Institute, National Research Council, Florence, Italy
}

Keywords: climate change, salt, temperature, water availability, whole plant physiology

Editorial on the Research Topic

Abiotic Stresses in Agroecology: A Challenge for Whole Plant Physiology

Abiotic stresses in agroecology are caused by climatic factors (e.g., temperature and precipitation extremes), pollutants (e.g., heavy metals, gaseous pollutants) and salinity. In the context of global change, climatic factors become particularly important. The alarming, progressive alterations in climate caused by rising levels of carbon dioxide $\left(\mathrm{CO}_{2}\right)$ and other greenhouse gases in the atmosphere are linked to well-known consequences of climate change; increase in average global temperature and the melting of the polar ice caps (IPCC, 2014). In addition to these global problems, increased frequencies and severities of extreme events including heat waves, drought periods or waterlogging have significant impacts at local and regional levels (Schär et al., 2004; IPCC, 2012; Kelley et al., 2015; Knutti et al., 2016). Such events may strongly influence crop yields and the quality of agricultural products. The effects of stresses imposed by these factors individually and in combination are relevant in the context of agroecology and in developing new agricultural concepts taking into account soil quality, biodiversity, sustainability as well as social and economic aspects (Tomich et al., 2011; Lai, 2015). This Research Topic focuses on the impacts of abiotic stress at the whole plant level, the mechanisms involved in the stress responses and the potential to increase stress tolerance in field crops and trees.

Elevated $\mathrm{CO}_{2}$ in the atmosphere caused by human activities is the major driver for global climate change that affects ambient temperature and precipitation patterns on global and regional scales, and water availability in soils as well as the frequency and severity of extreme events (IPCC, 2012, 2014). Atmospheric $\mathrm{CO}_{2}$ may also directly influence primary metabolism and thereby plant growth and productivity as reported by Long et al. (2006), Centritto et al. (2011), Hasegawa et al. (2013), Haworth et al., Haworth et al., Martinez-Lüscher et al. Free-air $\mathrm{CO}_{2}$ enrichment (FACE) facilities have been used to establish the impact of elevated $\mathrm{CO}_{2}$ on the efficiency of radiation, water and nitrogen utilization, overall crop yields (Dugas and Pinter, 1994; Long et al., 2006), and the interactions between sink structures (Hasegawa et al., 2013). In this Research Topic, Martinez-Lüscher et al. investigated interactions between elevated $\mathrm{CO}_{2}$ levels, ambient temperature and water availability in grapevine (Vitis vinifera L.) phenology from bud break to fruit maturation, while Haworth et al. addressed interactions between elevated $\mathrm{CO}_{2}$, stomatal control and photosynthetic performance. Haworth et al. argue that because of the tendency in free-air $\mathrm{CO}_{2}$ (FACE) experiments to publish more of significant results and less of nonsignificant results, the meta-analyses of results of such studies might lead to overestimation of the physiological impacts of rising $\mathrm{CO}_{2}$ levels in the atmosphere. Therefore while the direction and significance of impacts 
reported in individual studies are not questioned by these considerations (Haworth et al.), caution is recommended when extrapolating such findings to worldwide productivity, especially as the interactions between atmospheric $\mathrm{CO}_{2}$ levels and other environmental factors (e.g., temperature, water availability) and the physiological mechanisms behind these interactions remain to be further elucidated.

Water availability in the soil and water relations of plants are key parameters predicted to be influenced by global climate change through altered regional precipitation patterns. This subject was addressed in several papers (Jian et al.; Kunert et al.; Martinez-Lüscher et al.; Polania et al.; Zarrouk et al.). Drought effects on root architecture and nodule properties in legumes with symbiotic nitrogen fixation as well as the possibilities for genetic improvements were reviewed by Kunert et al. Extended drought periods not only affect the development and physiological functions of roots and vegetative shoots, but also influence redistribution of nutrients to pods and seeds of maturing beans (Polania et al.) or to ripening grape berries (Zarrouk et al.). From these reports it is evident that source/sink relationships are highly relevant in plants exposed to drought and perturbation affects the quantity and quality of yield. Salt stress is an important consideration in many regions (especially coastal zones) and while not directly related to global climatic change, there are some similarities to drought stress and interactions with other abiotic stress factors (Wang et al., 2003; Munns and Tester, 2008), for example microRNAs were found to be important for the germination of rapeseed (Brassica napus L.) seeds under drought or salt stress (Jian et al.). Transport processes across membranes are important for subcellular compartmentation (e.g., sequestration into the vacuole) as well as for long-distance transport processes (e.g., release into the root xylem followed by acropetal transport in the transpiration stream). A salt-specific mechanism was investigated in soybean (Glycine max (L.) Merr.) by Wei et al. These authors found that a $\mathrm{Cl}^{-} / \mathrm{H}^{+}$antiporter (GmCLC1) contributed to salt tolerance and was involved in the retention of $\mathrm{Cl}^{-}$ions in the roots and in decreasing the release to the shoot.

Besides the steady increase in average temperature caused by the elevated $\mathrm{CO}_{2}$ concentration in the air, more frequent and more severe extreme events including heat waves and also cold phases have been predicted by climate models (Schär et al., 2004; IPCC, 2012). Elevated temperature may influence photosynthetic performance (e.g., via decreased Rubisco activase activity as reported by Scafaro et al., 2016), stomatal regulation (Reynolds-Henne et al., 2010; Feller and Vaseva, 2014), floret fertility (Prasad et al.) or ripening berries (Zarrouk et al.). These effects, which are all related to the source/sink network, have been clearly documented, but the overall effects of heat on various plant species and the mechanisms behind these effects are not yet well understood. A perspective paper on limitations to grassland productivity by low temperature was contributed by Wingler and Hennessy to this Research Topic and addresses issues of seasonality, breeding and epigenetic changes. The risk for freezing damage in woody perennial plants was evaluated in the context of global climate change in an opinion paper contributed by Arora and Taulavuori. These authors refer to cold acclimation prior to the cold season, dormancy and deacclimation (including the risk of premature deacclimation) and discuss physiological processes involved as well as their regulation.

Cytokinin may play an important role in the perception of environmental stresses (Argueso et al., 2009). Two papers in this Research topic are focused on the role of cytokinin in the response of plants to abiotic stresses (Golan et al.; Paul et al.). Transgenic Arabidopsis plants characterized by an overproduction of cytokinin were found to be less droughtsusceptible and to be more productive under drought than control plants (Golan et al.). The avoidance of premature senescence in these drought-stressed plants and the mechanisms involved in the beneficial cytokinin effects were investigated. Paul et al. presented good evidence that cytokinin is important for the maintenance of meristematic functions in plants subjected to abiotic stress and that this protective effect in poplar (Populus $\times$ canescens (Aiton) Sm.) is important during the summer as well as during winter.

The response of plants to various abiotic stresses or to combinations of stresses is of practical relevance, since environmental disturbances are often characterized by coincidence of several factors (e.g., drought and elevated temperature) (Wang et al., 2003). Responses of plants to various stresses and combinations of stresses were addressed in several papers of this Research Topic (Gangadhar et al.; Martinez-Lüscher et al.; Zarrouk et al.). Gangadhar et al. characterized the functions of the thermo-tolerance gene StnsLTP1 in enhancing the activation of the antioxidant defense system, thus contributing to tolerance to multiple abiotic stresses in potato. Kopecky et al. explored the evolution of polyploidy within the fescue [Festuca pratensis subsp. apennina (De Not.) Hegi] species and how this knowledge can contribute to improved stress tolerance in Festulolium cultivars to produce climate change resilient grasses. As mentioned by these authors as well as by others, the elucidation of breeding strategies is a key aspect to support farmers in a changing climate with more frequent and more severe extreme events (Humphreys et al., 2014).

All aspects presented in this Research Topic are relevant in the context of the impact of abiotic stress, but not all relevant aspects could be included in this Research Topic. The following aspects remain to be addressed or further emphasized in the future:

(a) Additional abiotic stresses not included here (e.g., pollution, unbalanced nutrient supply).

(b) Timing of stress phases (starting time, duration, single phase or multiple phases).

(c) Interplay between various abiotic stresses including the mechanisms behind the interactions.

(d) Further integration of processes at the whole-plant level including recovery phases.

(e) Separation of species-specific and more general effects. 
(f) Identification of key proteins/genes for breeding (potential for improvements).

(g) Biophysical limits of crops to climatic extremes.

\section{AUTHOR CONTRIBUTIONS}

UF, AHK-S, and MC co-wrote this editorial based on the various contributions to this Research Topic.

\section{REFERENCES}

Argueso, C. T., Ferreira, F. J., and Kieber, J. J. (2009). Environmental perception avenues: the interaction of cytokinin and environmental response pathways. Plant Cell Environ. 9, 1147-1160. doi: 10.1111/j.1365-3040.2009. 01940.x

Centritto, M., Tognetti, R., Leitgeb, E., Střelcová, K., and Cohen, S. (2011). "Above ground processes: anticipating climate change influences," in Forest Management and the Water Cycle: An Ecosystem-Based Approach, vol. 212, Ecological Studies, eds M. Bredemeier, S. Cohen, D. L. Godbold, E. Lode, V. Pichler, and P. Schleppi (Dordrecht: Springer), 31-64.

Dugas, W. A., and Pinter, P. J. Jr. (1994). Introduction to the free-air carbon dioxide enrichment (FACE) cotton project. Agric. For. Meteorol. 70, 1-2. doi: 10.1016/0168-1923(94)90043-4

Feller, U., and Vaseva, I. I. (2014). Extreme climatic events: impacts of drought and high temperature on physiological processes in agronomically important plants. Front. Environ. Sci. 2:39. doi: 10.3389/fenvs.2014.00039

Hasegawa, T., Sakai, H., Tokida, T., Nakamura, H., Zhu, C., Usui, Y., et al. (2013). Rice cultivar responses to elevated $\mathrm{CO}_{2}$ at two free-air $\mathrm{CO}_{2}$ enrichment (FACE) sites in Japan. Funct. Plant Biol. 40, 148-159. doi: 10.1071/FP 12357

Humphreys, M., O’Donovan, S., Farrell, M., Gay, A., and Kingston-Smith, A. H. (2014). The potential of novel Festulolium $(2 \mathrm{n}=4 \mathrm{x}=28)$ hybrids as productive, nutrient-use-efficient fodder for ruminants. Food Energy Secur. 3, 98-110. doi: $10.1002 /$ fes 3.50

IPCC (2012). "Summary for policymakers," in Managing the Risks of Extreme Events and Disasters to Advance Climate Change Adaptation. A Special Report of Working Groups I and II of the Intergovernmental Panel on Climate Change, eds C. B. Field, V. Barros, T. F. Stocker, D. Qin, D. J. Dokken, K. L. Ebi, M. D. Mastrandrea, K. J. Mach, G.-K. Plattner, S. K. Allen, M. Tignor, and P. M. Midgley (Cambridge, MA: Cambridge University Press), 1-19.

IPCC (2014). "Climate change 2014: mitigation of climate change," in Contribution of Working Group III to the Fifth Assessment. Report of the Intergovernmental Panel on Climate Change, eds O. Edenhofer, R. Pichs-Madruga, Y. Sokona, E. Farahani, S. Kadner, K. Seyboth, A. Adler, I. Baum, S. Brunner, P. Eickemeier, B. Kriemann, J. Savolainen, S. Schlömer, C. von Stechow, T. Zwickel, and J. C. Minx (Cambridge, MA: Cambridge University Press), 1-1435.

Kelley, C. P., Mohtadi, S., Cane, M. A., Seager, R., and Kushnir, Y. (2015). Climate change in the fertile crescent and implications of the recent syrian drought. Proc. Natl. Acad. Sci. U.S.A. 112, 3241-3246. doi: 10.1073/pnas.1421533112

\section{ACKNOWLEDGMENTS}

We thank all authors of contributions to this Research Topic for preparing high-quality manuscripts under a tight time schedule and the reviewers for critically evaluating the papers and for further improving them with their questions, comments, and suggestions. AHK-S acknowledges strategic support to IBERS, Aberystwyth University, from the Biotechnology and Biological Sciences Research Council (BBSRC).

Knutti, R., Rogelj, J., Sedláček, J., and Fischer, E. M. (2016). A scientific critique of the two-degree climate change target. Nat. Geosci. 9, 13-19. doi: 10.1038/NGEO2595

Lai, R. (2015). Restoring soil quality to mitigate soil degradation. Sustainability 7 , 5875-5895. doi: 10.3390/su7055875

Long, S. P., Ainsworth, E. A., Leakey, A. D., Nösberger, J., and Ort, D. R. (2006). Food for thought: lower-than-expected crop yield stimulation with rising $\mathrm{CO}_{2}$ concentrations. Science 312, 1918-1921. doi: 10.1126/science.1114722

Munns, R., and Tester, M. (2008). Mechanisms of salinity tolerance. Annu. Rev. Plant Biol. 59, 651-681. doi: 10.1146/annurev.arplant.59.032607. 092911

Reynolds-Henne, C. E., Langenegger, A., Mani, J., Schenk, N., Zumsteg, A., and Feller, U. (2010). Interactions between temperature, drought and stomatal opening in legumes. Environ. Exp. Bot. 68, 37-43. doi: 10.1016/j.envexpbot.2009.11.002

Scafaro, A. P., Gallé, A., Van Rie, J., Carmo-Silva, E., Salvucci, M. E., and Atwell, B. J. (2016). Heat tolerance in a wild Oryza species is attributed to maintenance of Rubisco activation by a thermally stable Rubisco activase ortholog. New Phytol. 211, 899-911. doi: 10.1111/nph.13963

Schär, C., Vidale, P. L., Lüthi, D., Frei, C., Häberli, C., Liniger, M. A., et al. (2004). The role of increasing temperature variability in European summer heatwaves. Nature 427, 332-336. doi: 10.1038/nature02300

Tomich, T. P., Brodt, S., Ferris, H., Galt, R., Horwath, W. R., Kebreab, E., et al. (2011). Agroecology: a review from a global-change perspective. Annu. Rev. Environ. Resour. 36, 193-222. doi: 10.1146/annurev-environ-012110-1 21302

Wang, W. X., Vinocur, B., and Altman, A. (2003). Plant responses to drought, salinity and extreme temperatures: towards genetic engineering for stress tolerance. Planta 218, 1-14. doi: 10.1007/s00425-003-1105-5

Conflict of Interest Statement: The authors declare that the research was conducted in the absence of any commercial or financial relationships that could be construed as a potential conflict of interest.

Copyright (C) 2017 Feller, Kingston-Smith and Centritto. This is an open-access article distributed under the terms of the Creative Commons Attribution License (CC BY). The use, distribution or reproduction in other forums is permitted, provided the original author(s) or licensor are credited and that the original publication in this journal is cited, in accordance with accepted academic practice. No use, distribution or reproduction is permitted which does not comply with these terms. 